\section{The Electron Microscope}

By Dr. V. E. Cosslett. (Sigma Introduction to Science, 8.) Pp. viii $+128+12$ plates. (London: Sigma Books, Ltd., 1947.) 7s. 6d. net.

7 HIS little book can be confidently recommended to those for whom it is written-the biologist and others seeking information about a new tool and the layman interested in recent scientific advances. It contains a non-mathematical account of the principles underlying the construction of an electron microscope. Starting with a description of the properties of an optical lens and the formation of an image by rays of light, the book proceeds to develop the analogy with electron lenses of both magnetic and electrostatic type. The account is at all times clear and simple; and the large number of illus. trations and plates make the book easy to read and to understand.

The book concludes with two chapters on the present uses and future possibilities of the electron microscope. The first of these serves to emphasize the rapidity with which this new method of investigating the fine structure of matter has been exploited both in fundamental and industrial research. The second suggests that further developments are still possible and are being actively pursued. G. D. P.

\section{Les mesures physiques}

Par Albert Pérard. (Que sais-je ?, No. 244.) Pp. 136. (Paris: Presses universitaires de France, 1947.) n.p.

TN this paper-covered pocket edition, one of the wall-known 'Que sais-je?' series, the director of the Bureau International des Poids et Mesures gives an authoritative, concise, and logical account of the important part played by measurement in science. The first chapter deals with the general principles and methods of measurement, and errors of observation. The following chapters discuss, in terms of the fundamental standards, the measurement of length, time and mass, and electrical measurements; and, since a knowledge of the temperature is essential for the exact specification of the fundamental quantities, a further chapter describes the methods used to measure temperature. The final chapter indicates briefly the principles of measurement of several other physical quantities, and an appendix tabulates equivalents of the principal units.

It is no easy task to deal adequately with the subject of measurement in such a small volume, and the author is to be congratulated on the skilful way in which he has chosen and handled his material. Unnecessary detail is avoided, and only a few absolutely essential references are given, so that even those possessing only a slight knowledge of physics will have no difficulty, when reading this book, in appreciating the basic principles and methods of physical measurement.

S. WEINTROUB

\section{Simple Experiments with Insects}

By Dr. H. Kalmus. Pp. xii +132 . (London : William Heinemann, Ltd., 1948.) 7s. $6 d$.

$\mathrm{T}$ $\mathrm{HE}$ surest way to arouse interest in a scientific subject is to make it interesting; to perform actual experiments is one way of doing this. In this little book Dr. Kalmus describes more than a hundred experiments in insect behaviour and physiology for the benefit of amateurs or of school children and their teachers. The experiments range from such simple things as putting a bee in a bottle and showing that it produces water, or catching a fly in the hand, to quite difficult experiments such as the comparative rearing of Drosophila on synthetic media or studying the optomotor reactions of the mosquito. Even with the help of the short explanations which accompany the descriptions, it is unlikely that the amateur will grasp the significance of all the experiments; but many of them are well calculated to excite his interest, and the book should prove a useful complement to the observations of insects in the field. It is likely to be useful, too, for university teachers of zoology. A few errors may be noted : the yolk is not formed by the accessory glands (p. xii); hæmoglobin is not broken down beyond hæmatin in the mosquito (p.15) ; on p. 20 'gills' are called 'tracheæ'; on p. 83 the book louse is called Anthrenus.

V. B. WIGGLESWORTH

Guide to the Study of the Anatomy of the Shark, Necturus, and the Cat

By Prof. Samuel Eddy, Prof. Clarence P. Oliver and Asst. Prof. John P. Turner. Second edition. Pp. vii+115. (New York: John Wiley and Sons, Inc.; London : Chapman and Hall, Ltd., 1947.) 12s. net.

HIS admirable little book, which was designed 1 for students of the University of Minnesota, is accurately described in its title. It gives the salient features of the anatomy of the three animals with which it deals in the form of directions for their dissection. It has the virtue that it is concise, but one feels that students might have been helped by more detailed statements of dissection procedures. Unlike many British text-books, there is some treatment of the muscles; it is perhaps to be regretted that they were not a little more fully treated in the spiny dog-fish. The illustrations are rather few but they are clear and pleasant to look at ; the last point is important, as increasing the likelihood that they will be studied. It would have been an advantage to have given some very simple sketches showing dissection methods. The book is clearly printed on thick paper, the pages held together between card covers by metal rings which enable the book to lie flat on a bench.

P. D. F. Murray

\section{The Psychology of Industry}

By Prof. James Drever. Second edition, revised. Pp. $x+151$. (London: Methuen and Co., Ltd., 1947.) 7s, 6d. net.

THE appearance of a second edition of this work some twenty-six years after the original is a tribute to the work of a pioneer. During the First World War experimental psychologists made one or two attempts to show how science could appreciably add to the productivity of industry. By the time of the Second World War the more up-to-date industrialists had realized that the nineteenth-century stress on material and monetary factors in industry had been greatly overdone and that efficiency could only be approached when as much attention was paid to the human factor. Prof. Drever's book is a record of the work done by himself and other investigators between the two wars. While it pays little attention to developments in industrial relations since that time, it is still a worthy guide for all who are seeking to provide optimum satisfaction to workers in industry and, concurrently, to raise the overall level of industry's productive capacity.

T. H. HAWkINS 